\title{
TESTIMONIA DE PHILONE EIVSQVE SCRIPTIS
}

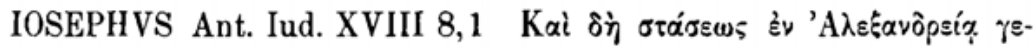

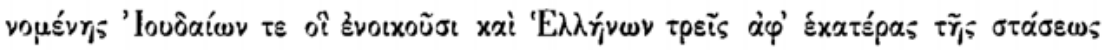

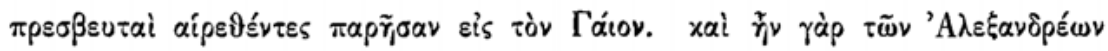

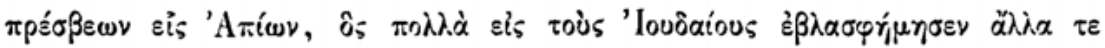

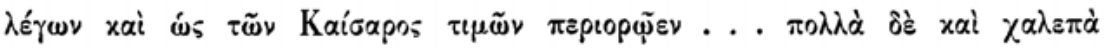
'A

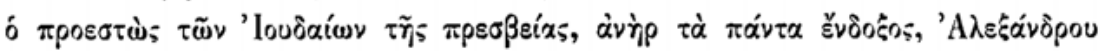

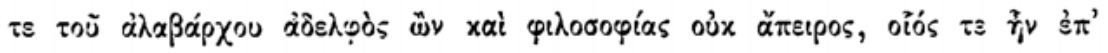

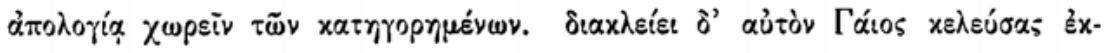

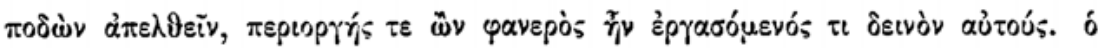

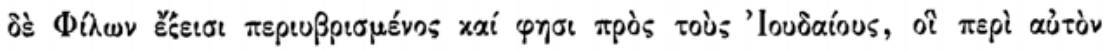

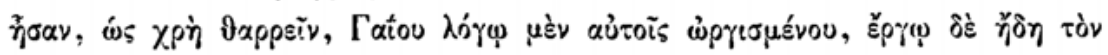

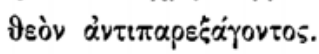

CLEMENS ALEXANDRINVS Strom. I 334 P. 'Eppquvésı dè ó $\Phi i$ -

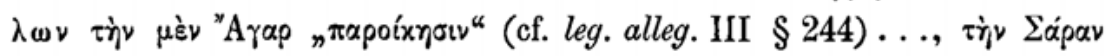

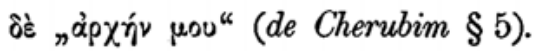

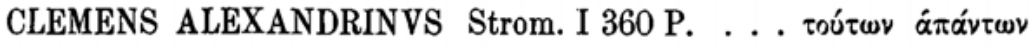

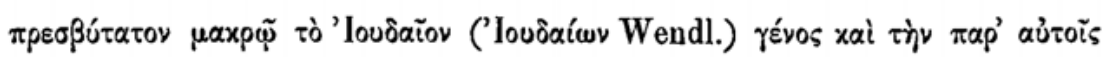

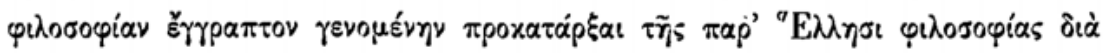

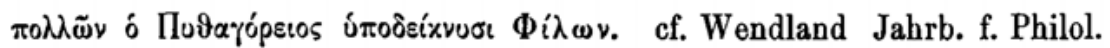
Suppl. XXII p. 770.

CLEMENS ALEXANDRINVS Strom. I 413 P. . . E żv ò

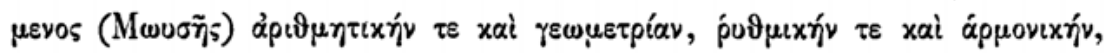

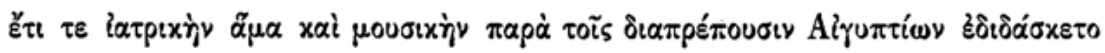

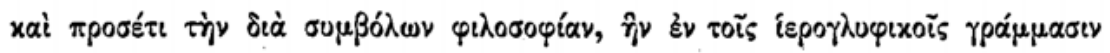

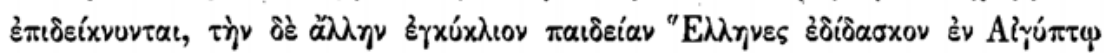




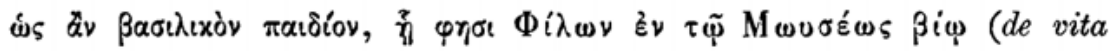
Mos. I 5 Mang. II 84).

CLEMENS ALEXANDRINVS Strom. II 482 P. . . . ai $\gamma \dot{\alpha} \rho \mu \varepsilon \gamma \alpha \dot{\lambda} \alpha t$

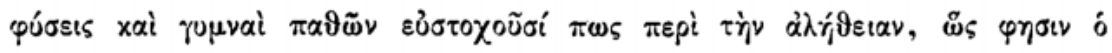

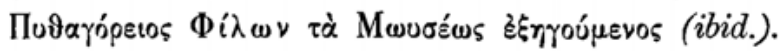

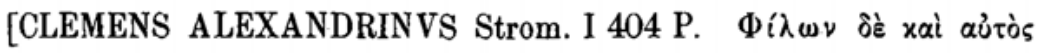

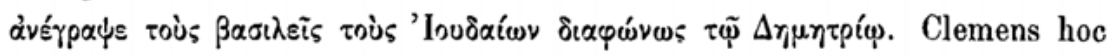
loco Philonem Byblium, non Alexandrinum, respexisse videtur.]

ORIGENES Comment. in Ev. Matth. XV 3 (t. III p. 331 Lomm.)

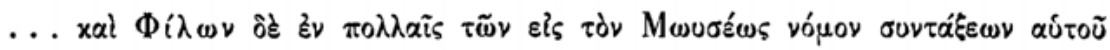

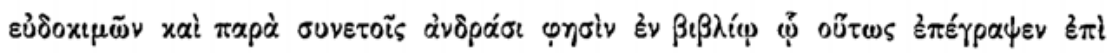

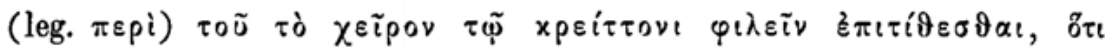

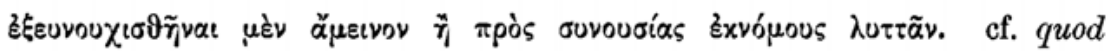
deter. pot. insidiari soleat $\S 176$ p. 297,19.

ORIGENES Comment. in Ev. Matth. XVII 17 (t. IV p. 124 Lomm.)

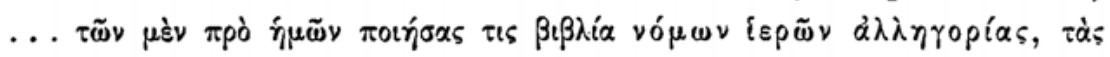

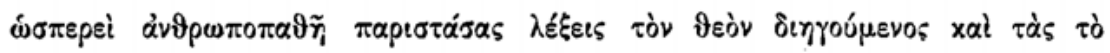

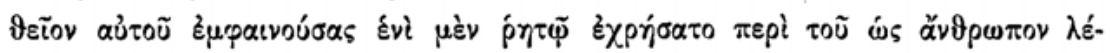

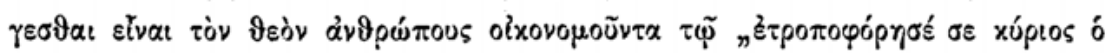

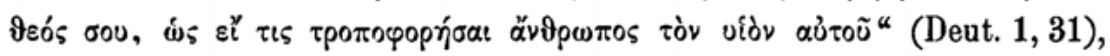

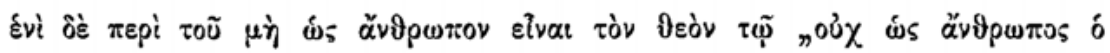

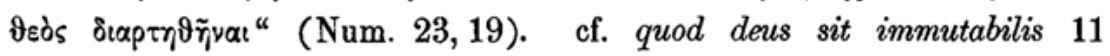
Mang. I 280. de somniis I 40 Mang. I 656.

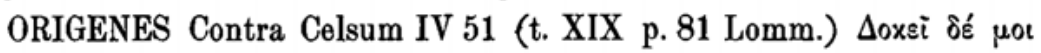

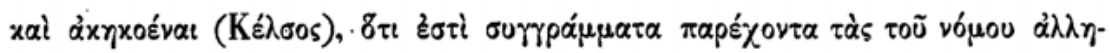

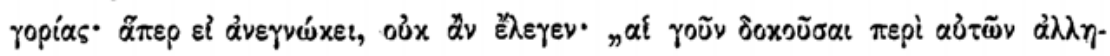

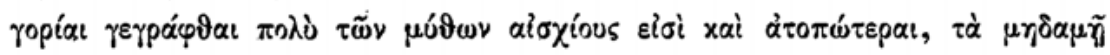

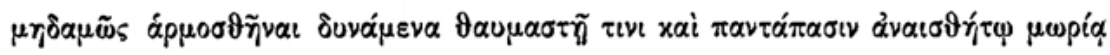

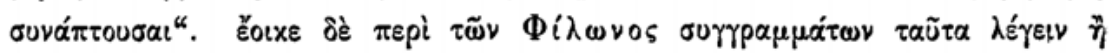

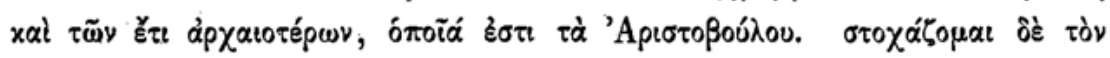

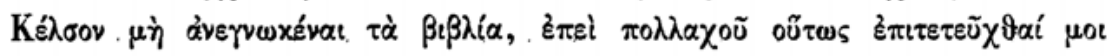

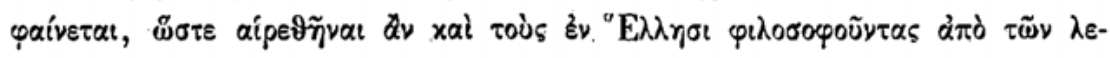

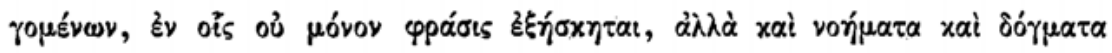

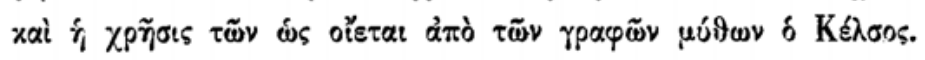


ORIGENES Contra Celsum VI 21 (t. XIX p. 336 Lomm.) Mwvor̃

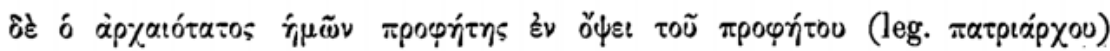

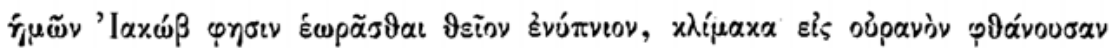

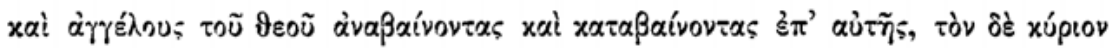

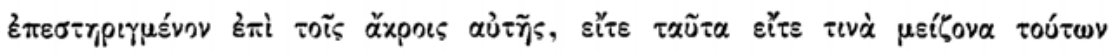

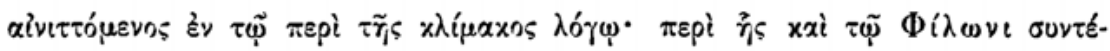

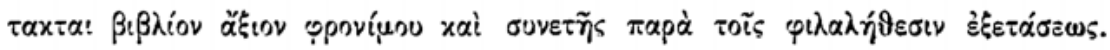
cf. de somniis I init.

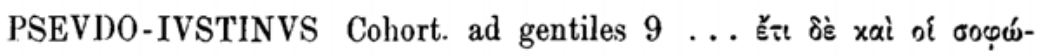

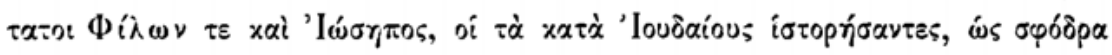

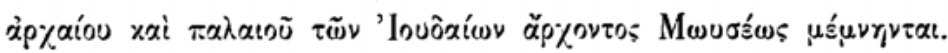

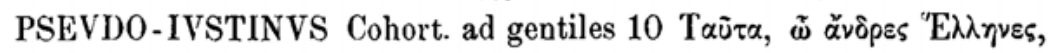
oi š

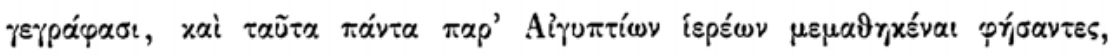

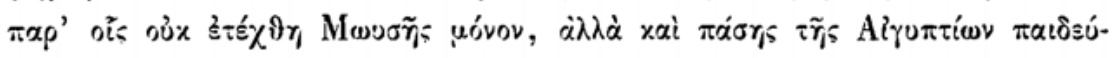

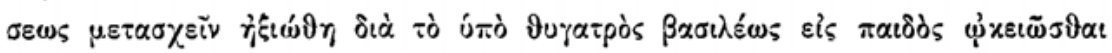

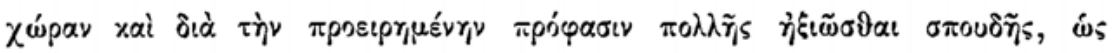

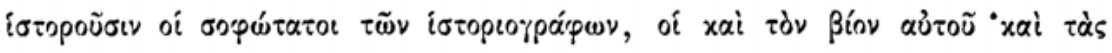

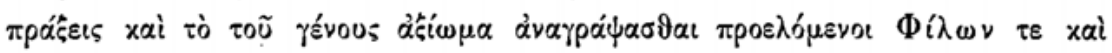

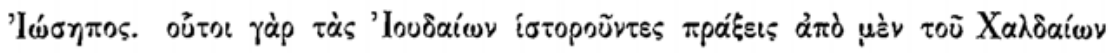

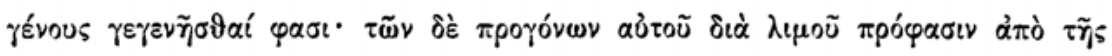

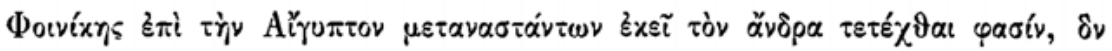

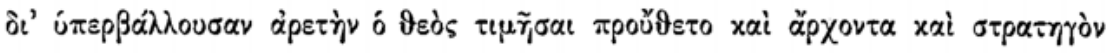

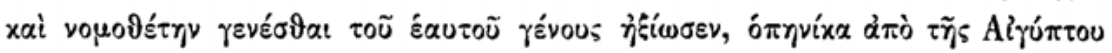

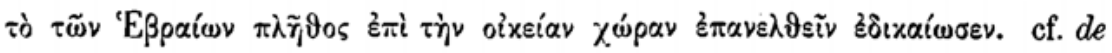
vita Mosis I init.

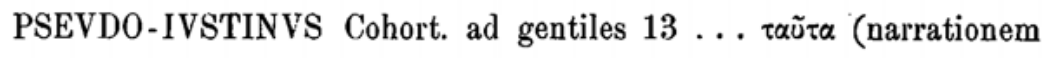

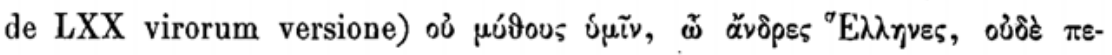

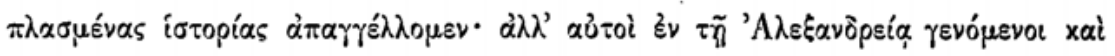

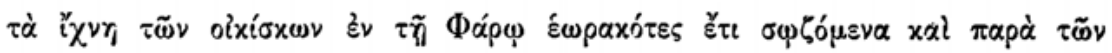

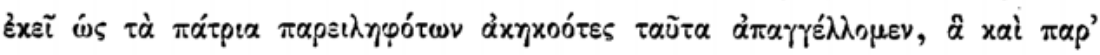

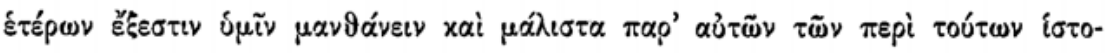

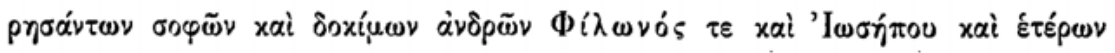
$\pi \lambda \varepsilon$ cóvew. cf. de vita Mos. II 5 sqq. 


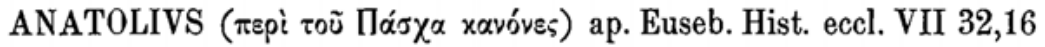

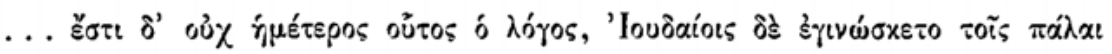

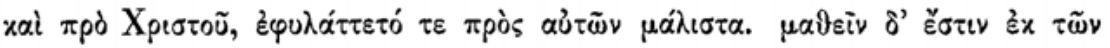

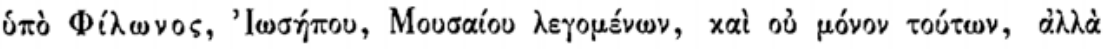

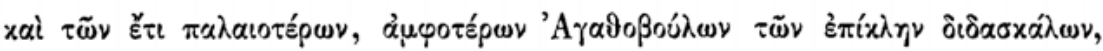

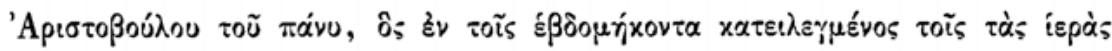

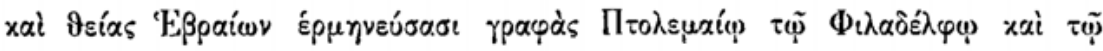

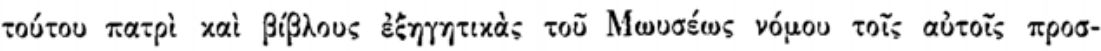

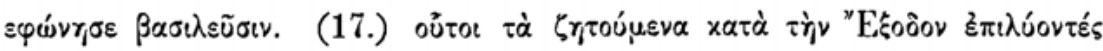

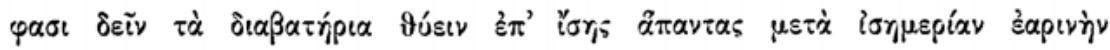

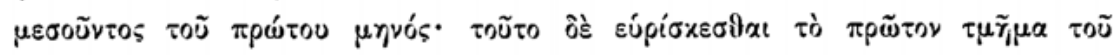

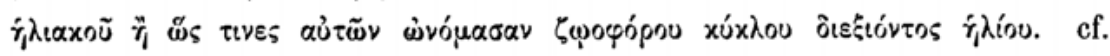
Quaest. in Exod. I § 1.

PSEVDO-CHRYSOSTOMVS Or. in Pascha VII (Migne Patrol. gr.

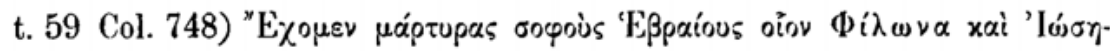

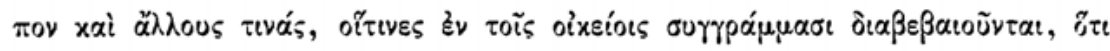
oủ ốva

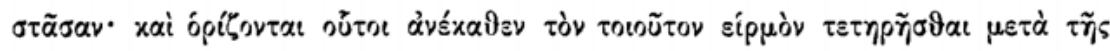

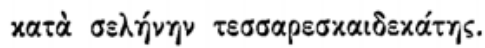

EVSEBIVS Chron. ad a. Abr. 2055: Flaco in Iudaeos fraudes facienti consentientes turbae Alexandrinorum varios cruciatus in eos excitabant synagogamque eorum appellatam imaginibus statuis aris et victimis polluebant. Philon in eo libro, quem ipse ad Flacum scripsit, (haec) refert, si quidem ipse quoque aderat, dum haec perficerentur, atque legationis responsum ad Gaium deportandum suscepit.

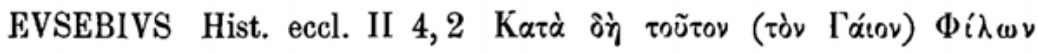

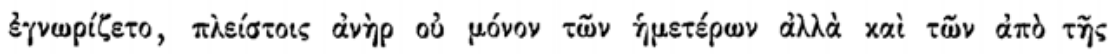

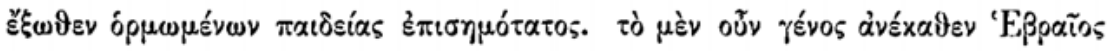

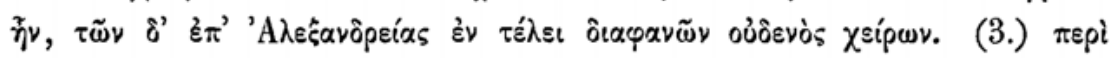

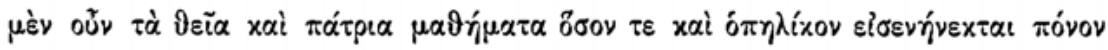

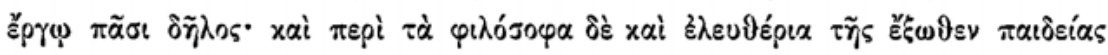

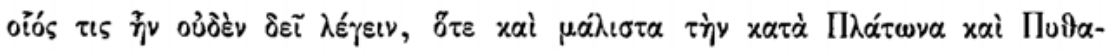

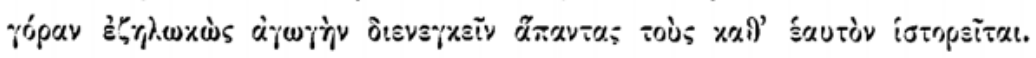




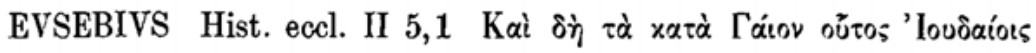

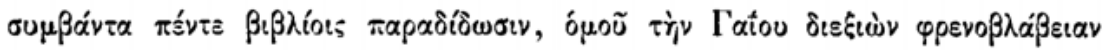

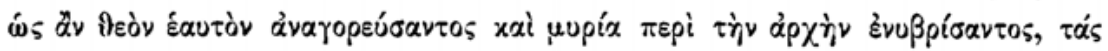

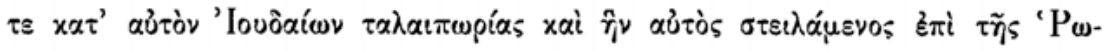

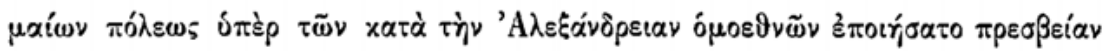

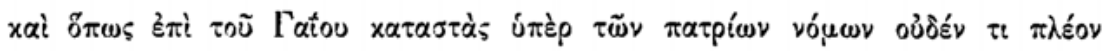

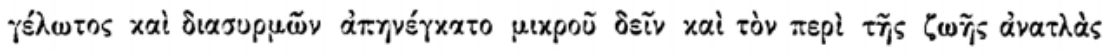

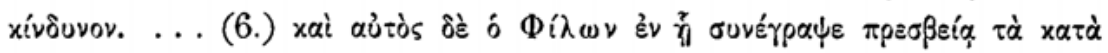

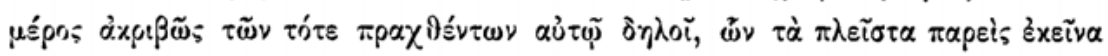

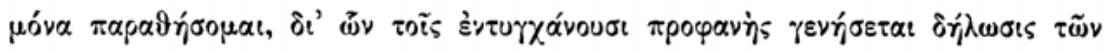

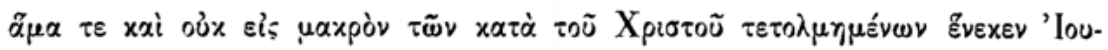

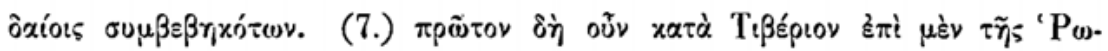

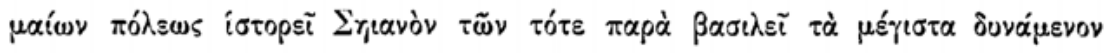

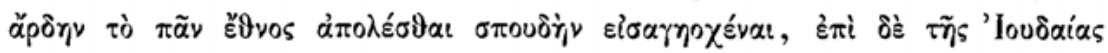

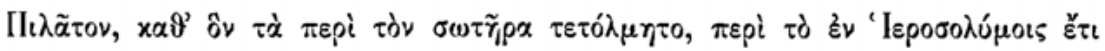

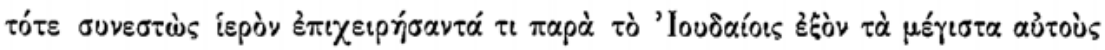

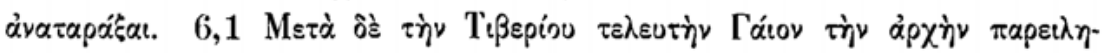

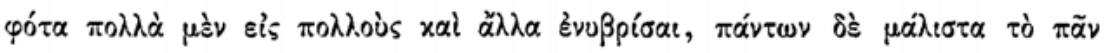

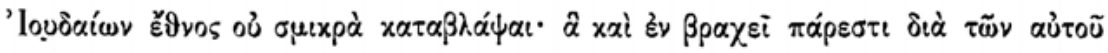

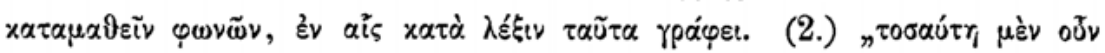

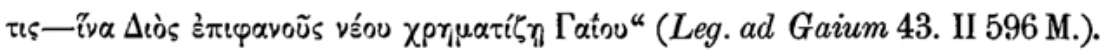

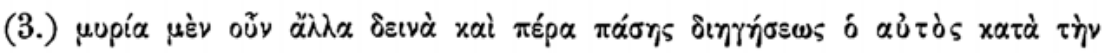

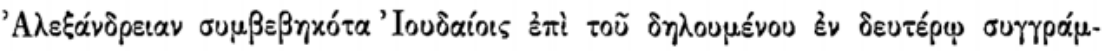

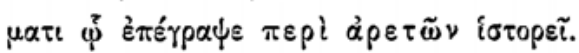

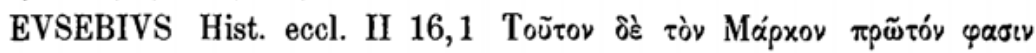

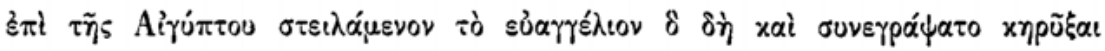

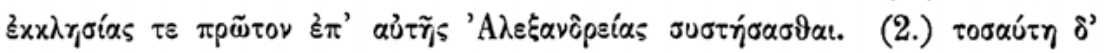

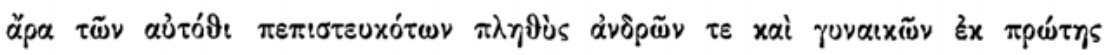

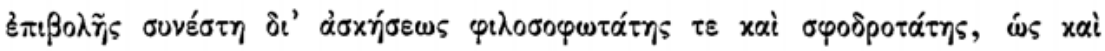

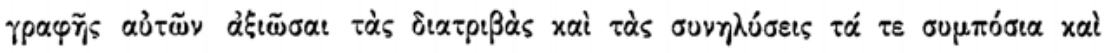

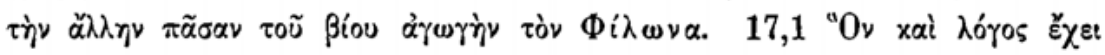

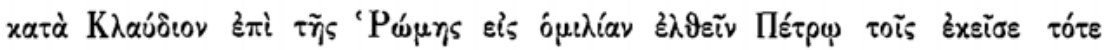

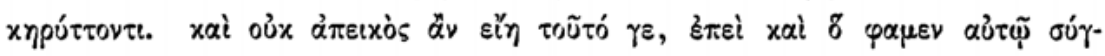

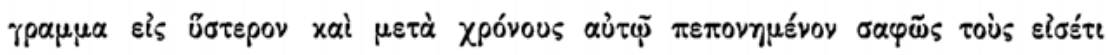

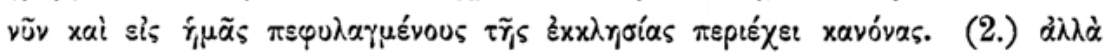




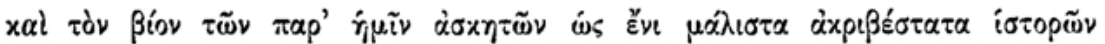

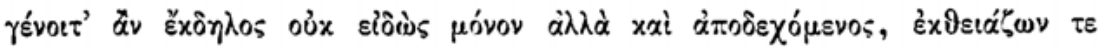

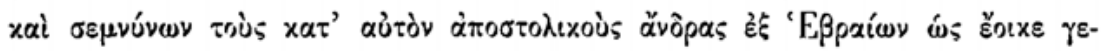

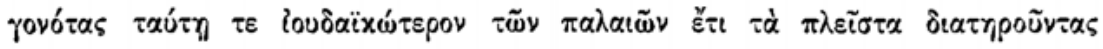

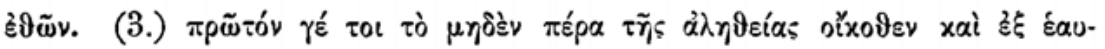

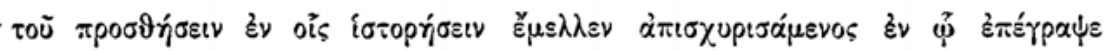

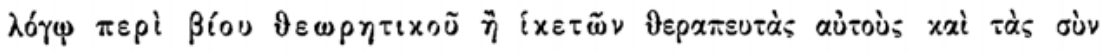

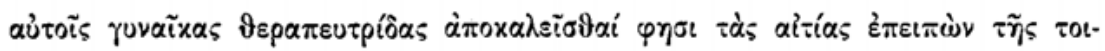

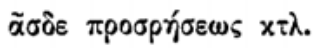

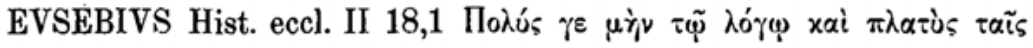

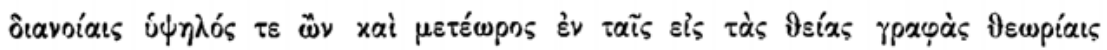

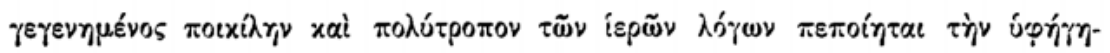

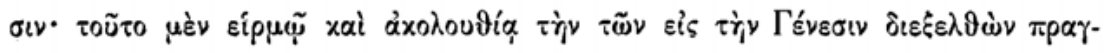

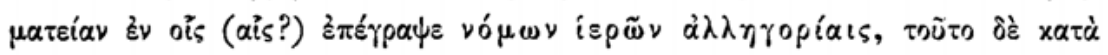

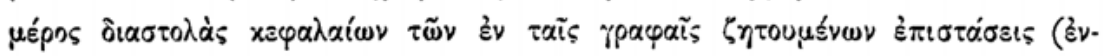

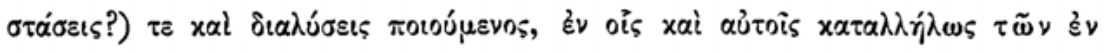

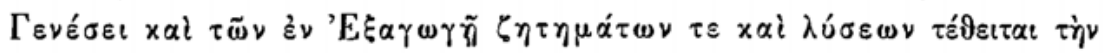

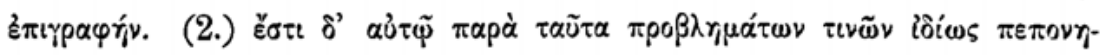

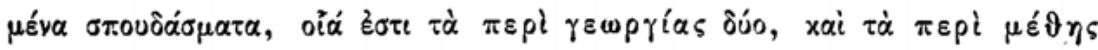

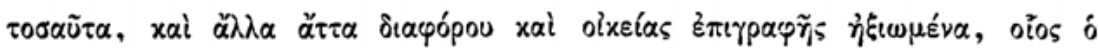

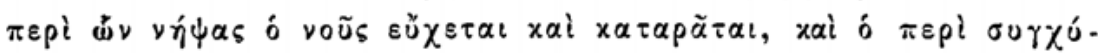

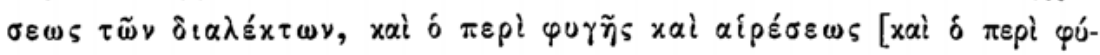

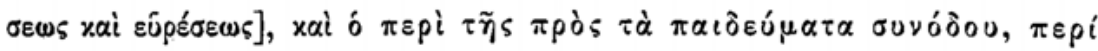

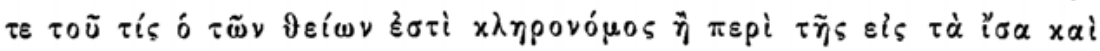

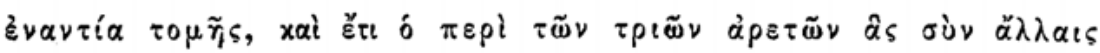

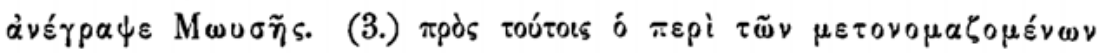

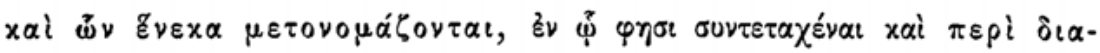

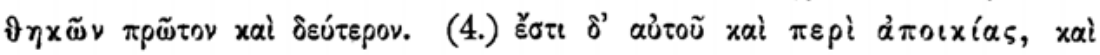

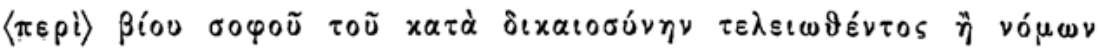

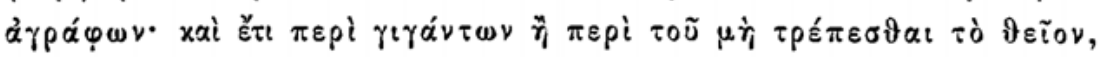

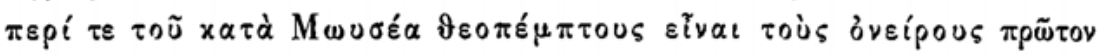

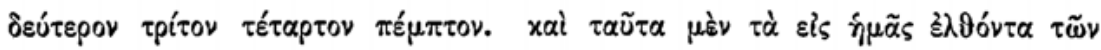

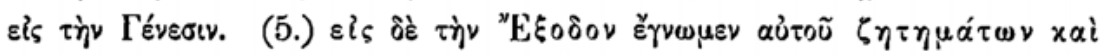

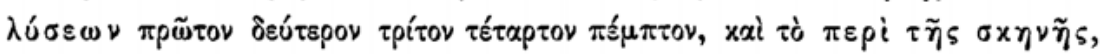

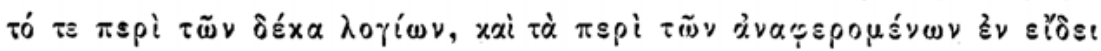




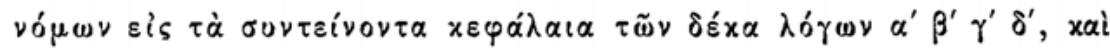

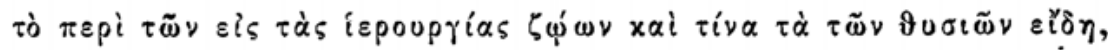

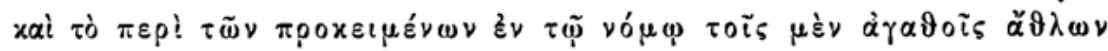

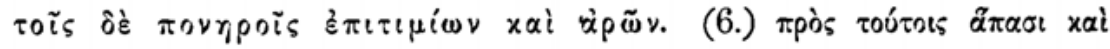

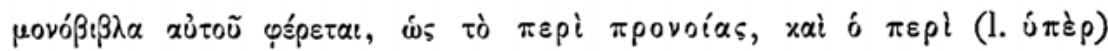

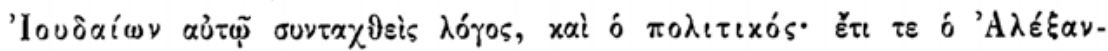

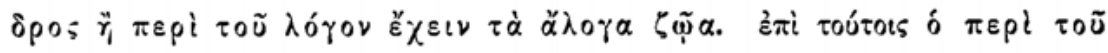

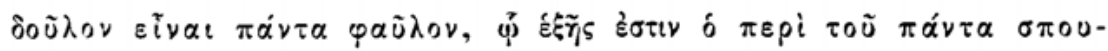

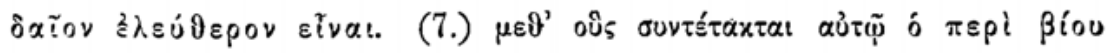

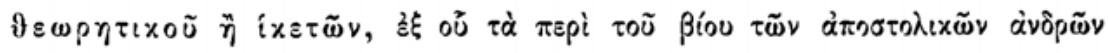

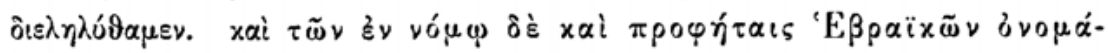

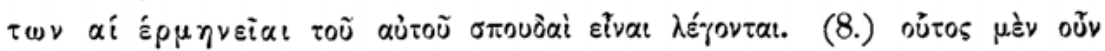

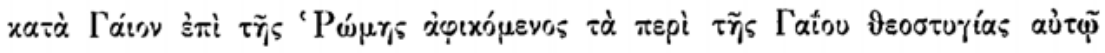

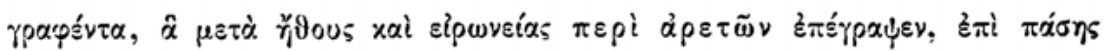

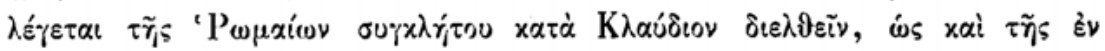

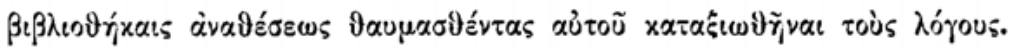

HIERONYMVS De vir. inl. 11 Philon Iudaeus, natione Alexandrinus, de genere sacerdotum, idcirco a nobis inter scriptores ccclesiasticos ponitur, quia librum de prima Marci evangelistae apud Alexandriam scribens ecclesia in nostrorum laude versatus est non solum eos ibi sed in multis quoque provinciis esse memorans et habitacula eorum dicens monasteria. ex quo apparet talem primum Christo credentium fuisse ecclesiam, quales nunc monachi imitantur et cupiunt, ut nihil cuiusquam proprium sit, nullus inter eos dives, nullus pauper, patrimonia egentibus dividantur, orationi vacetur et psalmis, doctrinae quo-
[Sophronii] versio graeca.

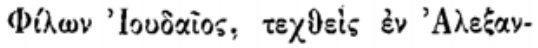

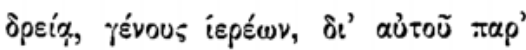

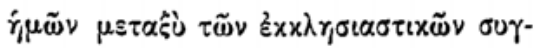

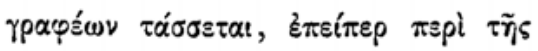

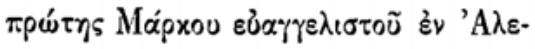

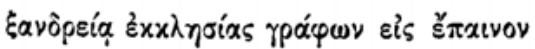

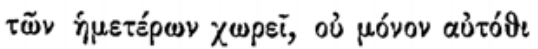

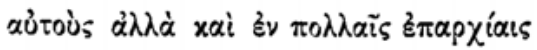

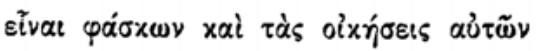

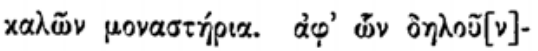

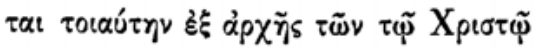

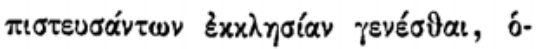

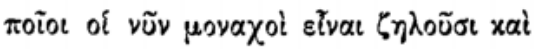

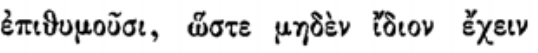

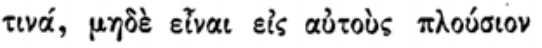

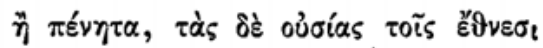

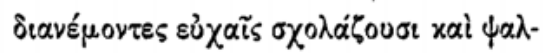


que et continentiae, quales et Lucas refert primum Hierosolymae fuisse credentes. aiunt hunc sub Gaio Caligula Romae periclitatum, quo legatus gentis suae missus erat; cum secunda vice venisset ad Claudium, in eadem urbe locutum fuisse cum apostolo Petro eiusque habuisse amicitias et ob hanc causam etiam Marci discipuli Petri apud Alexandriam sectatores ornasse laudibus suis. extant huius praeclara et innumerabilia opera in quinque libros Moyse ${ }^{1}$ ): de confusione linguarum liber unus, [de natura et inventione liber unus] ${ }^{2}$ ), de his quae sensu precamur et detestamur liber unus, de eruditione liber unus, de herede divinarum rerum liber unus, de divisione aequalium et contrariorum liber unus, de tribus virtutibus liber unus, quare quorundam in scripturis mutata sint nomina liber unus, de pactis libri duo, d'e vita sapientis liber unus, de gigantibus liber unus, quod somnia mittantur a Deo libri quinque, Quaestionum et solutionum in Exodum libri quinque, de tabernaculo et decalogo libri quattuor, nec non de

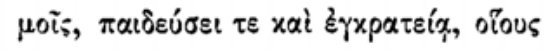

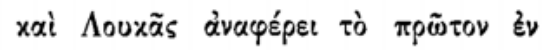

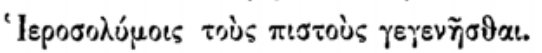

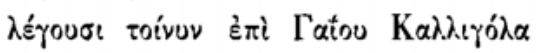

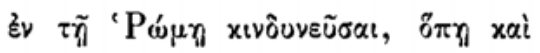

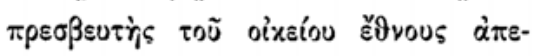

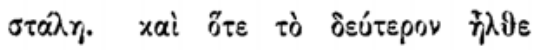

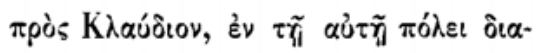

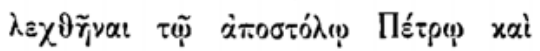

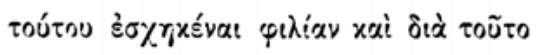

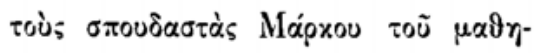

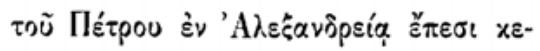

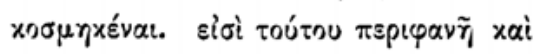

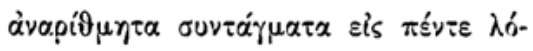

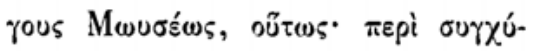

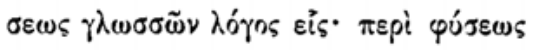

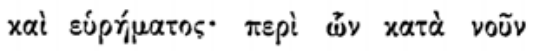

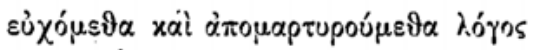

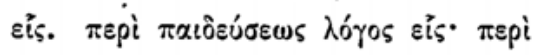

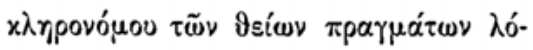

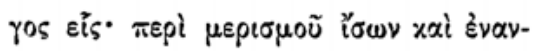

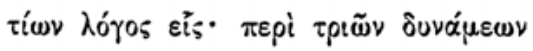

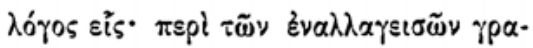

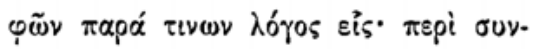

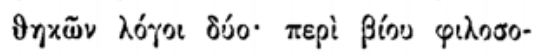

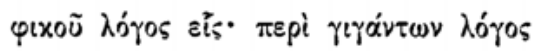

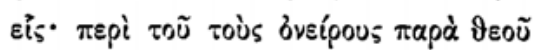

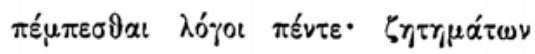

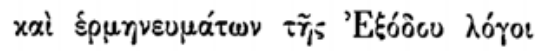

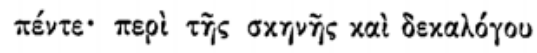

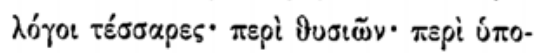

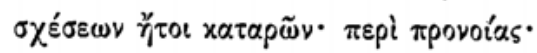

1) sic $\mathrm{AB}$, in quibus libros Mosi $\mathrm{C}$, in quibus ex libris Moysi D (Bernoulli).

2) om. C.D. 
victimis et repromissionibus sive maledictis, de providentia, de Iudaeis, de conversatione vitae, de Alexandro et quod propriam rationem muta habeant, et quod omnis insipiens servus sit, et de vita nostrorum liber, de quo supra diximus, id est de apostolicis viris,

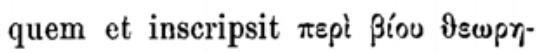

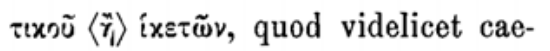
lestia contemplentur et semper orent Deum. et sub aliis indicibus de agricultura libri duo, de ebrietate libri duo. sunt et alia eius monumenta ingenii, quae in nostras manus non pervenerunt. de hoc vulgo apud Graecos dicitur: $\ddot{\eta_{j}} \Pi \lambda \dot{\alpha}-$ $\tau \omega \nu \varphi \varphi\left(\lambda \omega v i \zeta \varepsilon t \dot{\eta} \Phi_{i} \lambda \omega \nu \pi \lambda \alpha \tau \omega v^{\prime} \zeta \varepsilon t\right.$, id est aut Plato Philonem sequitur aut Platonem Philo; tanta est similitudo sensuum et eloquii ${ }^{1}$ ).

HIERONYMVS Lib. interpret. hebr. nominum praef. (Lagarde Onomastica Sacra p. 1): Philo, vir disertissimus Iudaeorum, Origenis quoque testimonio comprobatur edidisse librum hebraicorum nominum eorumque etymologias iuxta ordinem litterarum e latere copulasse. qui cum vulgo habeatur a Graecis et bibliothecas orbis impleverit, studii mihi fuit in latinam eum linguam vertere. verum tam dissona inter se exemplaria repperi et sic confusum ordinem, ut tacere melius iudicaverim quam reprehensione quid dignum scribere. itaque hortatu fratrum Lupuli et Valeriani, qui me putant aliquid in hebraea lingua notitia profecisse, et rei ipsius utilitate commotus singula per ordinem Scripturarum volu-

1) Omisi testimonia ceterorum scriptorum qui ab Eusebio vel a Rufino omnino pendent, ut Freculphi Chron. II 1,11 et Nicephori Hist. eccl. II 15-17. 
mina percucurri et vetus aedificium nova cura instaurans fecisse me reor quod a Graecis quoque adpetendum sit.

HIERONYMVS Praef. in librum Iob: . . quod si cui videtur incredulum, metra scilicet esse apud Hebraeos et in morem nostri Flacci Graecique Pindari et Alcaei et Sappho vel Psalterium vel Lamentationes Ieremiae vel omnia ferme Scripturarum cantica comprehendi, legat Philonem Iosephum Origenem Caesariensem Eusebium et eorum testimonio me verum dicere comprobabit.

HIERONYMUS Commentar. in Danielem I 3 Philo arbitratur linguam Hebraeorum ipsam esse Chaldaicam, quia Abraam de Chaldaeis fuerit.

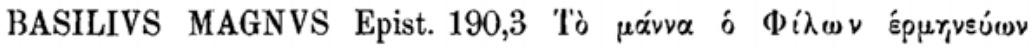

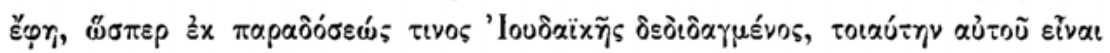

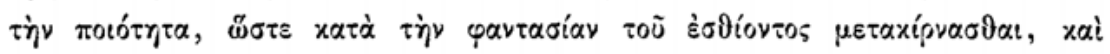

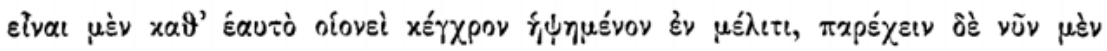

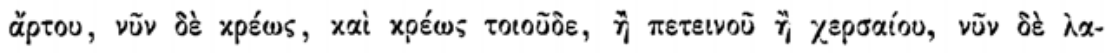

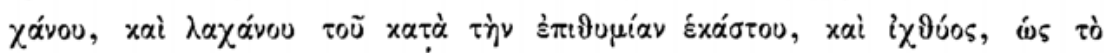

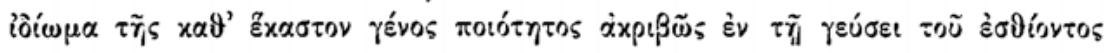
$\delta เ \alpha \sigma ழ ่ \zeta \varepsilon \sigma \vartheta \alpha t$.

AMBROSIVS De Paradiso 4,25 ... Haec duo ab homine requiruntur, ut et operibus nova quaerat et parta custodiat, quod est generale. Philon autem, quoniam spiritalia Iudaico non capiebat affectu, intra moralia se tenuit, ut diceret haec duo quaeri, opera in agro, custodiam domus. et quamvis paradisus operibus, inquit, ruralibus non egeret, tamen quia primus homo lex posteritatis futurus erat, ideo legitimi etiam in paradiso speciem suscepit laboris, ut nos ad operationem et custodiam debiti officii et hereditariae successionis munus astringeret. cf. Quaest. in Genesin lib. I $\$ 14$.

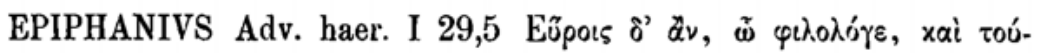

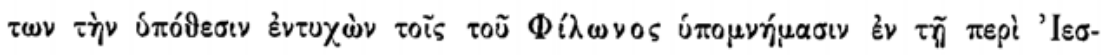

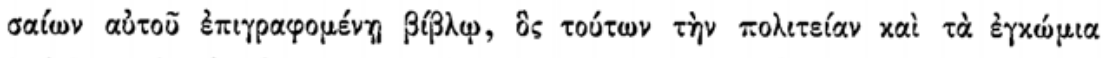

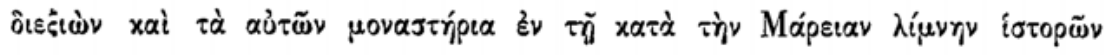

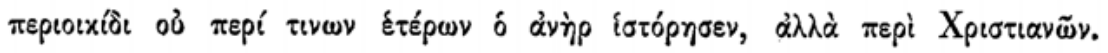




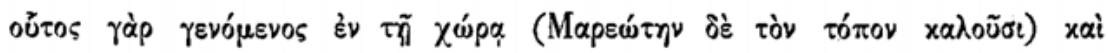

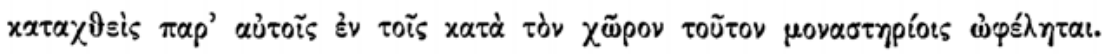

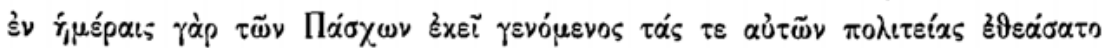

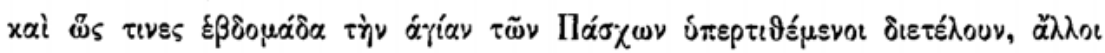

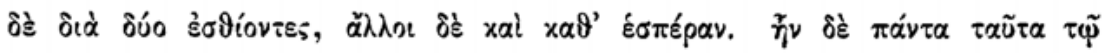

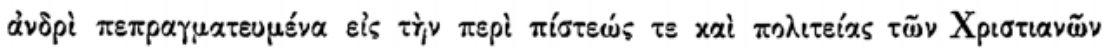
úлó 1865) p. 135.

AVGVSTINUS Contra Faustum XII 39 ... vidit hoc Philo quidam, vir liberaliter eruditissimus unus illorum (Iudaeorum), cuius eloquium Graeci Platoni aequare non dubitant, et conatus est aliqua interpretari ${ }^{1}$ ), non ad Christum intellegendum, in quem non crediderat, sed ut inde magis adpareret, quantum intersit, utrum ad Christum referas omnia, propter quem vere sic dicta sunt, an praeter illum quaslibet coniecturas quolibet mentis acumine persequaris ... ut enim quiddam eiusdem Philonis commemorem, arcam diluvii secundum rationem humani corporis fabricatam volens intellegi tamquam membratim omnia pertractabat. cui subtilissime numerorum etiam regulas consulenti congruenter occurrebant omnia, quae ad intellegendum Christum non inpedirent, quoniam in corpore humano etiam ille humani generis salvator adparuit, nec tamen cogerent, quia corpus humanum est utique et hominum ceterorum. at ubi ventum est ad ostium, quod in arcae latere factum est, omnis humani ingenii coniectura defecit. ut tamen aliquid diceret, inferiores corporis partes, qua urina et fimus egeruntur, illo ostio significari ausus est credere, ausus et dicere, ausus et scribere. non mirum, si ostio non invento sic erravit. quodsi ad Christum transisset, ablato velamine sacramenta ecclesiae manantia ex latere hominis illius invenisset. cf. Quaest. in Gen. II § $1 \mathrm{sqq}$.

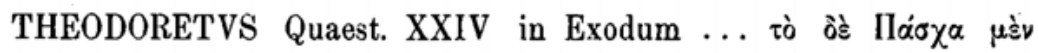

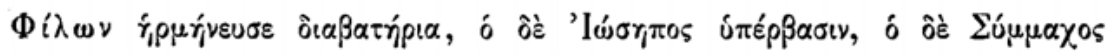

1) videntur deesse nonnulla. 


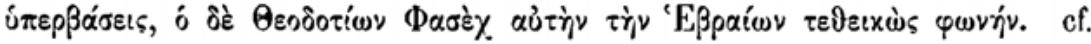
Quaest. in Exod. I § 4. de vita Mos. III 29 Mang. II 169.

IN'TERPRETIS ARMENII praefatio in Philonis libros de Providentia (p. VII Auch.): Magnae sapientiae vir Philo Israelita fuit, sed non constat, ex qua ex duodecim tribubus, si quidem dispersae non semel fuerant a captivantibus. nam etsi Cyri Darii et Artaxerxis temporibus reversae fuissent sub Zorobabel Esdra et Nehemia, regnante tamen Antiocho Maccabaeorum aetate iterum dispersae sunt partim in Libyam atque Alexandriam Aegypti partim in alias regiones, utcumque tulit sors. hinc confusae sunt atque permixtae genealogiae, domus quoque possessionesque acquisitae in regionibus, in quas captivae ductae fuerant. quod ex ipso Actorum libro constat, ubi legimus Hebraeos bene multos ascendisse Ierusalem festis diebus imminentibus ex Parthia, Media, Elamitide, Mesopotamia, Phrygia, Pamphylia aliisque proximis locis et remotis; eos vero qui cum Stephano contendebant seque legis aemulatores venditabant ex Alexandria magna ex parte fuisse. ex horum numero et hic Philo fuisse creditur: etenim per ea tompora praefectus erat civitatis Alexandriae et legatus Romam missus ad Gaium Caesarem reversus est inde cum ignominia; quod tempore praedicationis Petri Romae contigisse testatur Eusebius Pamphili.

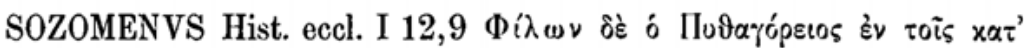

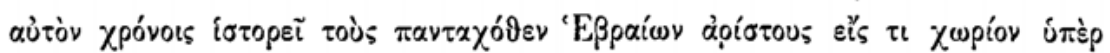

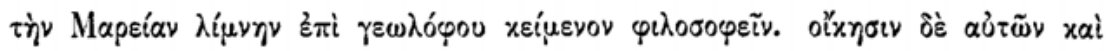

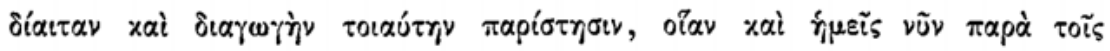

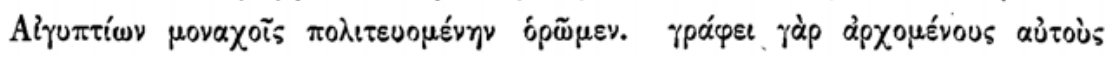

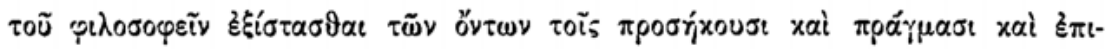

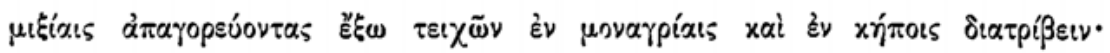

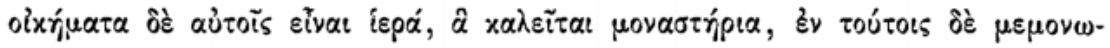

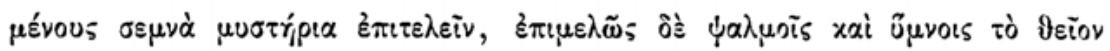

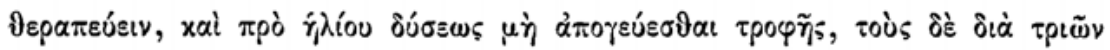

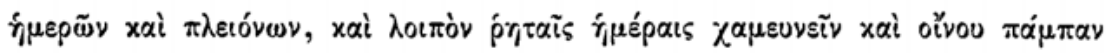

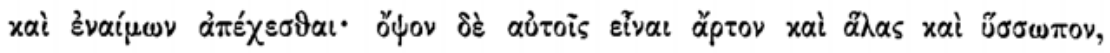

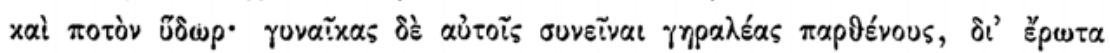




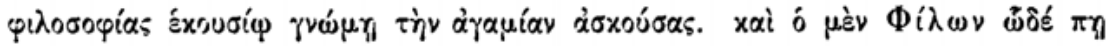

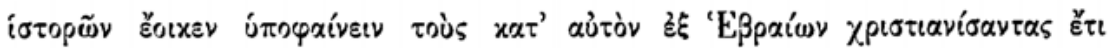

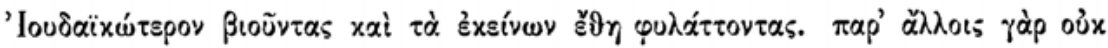

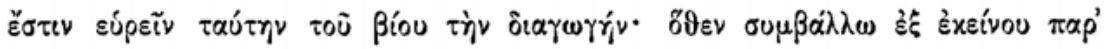

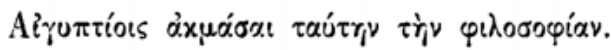

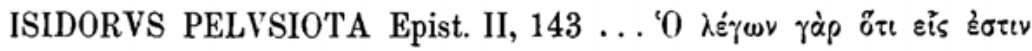

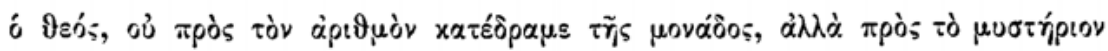

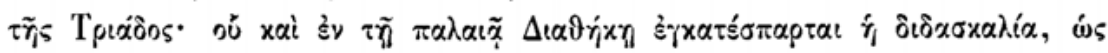

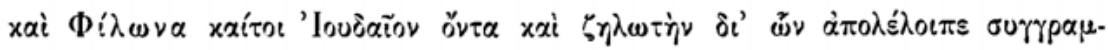

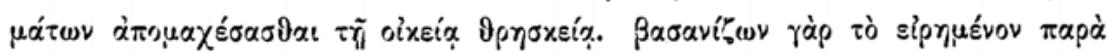

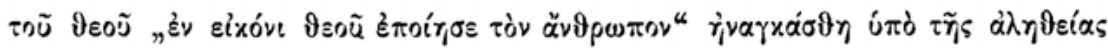

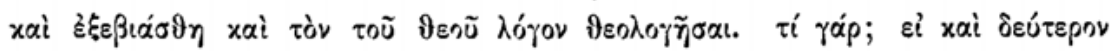

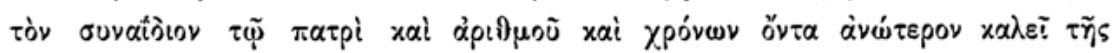

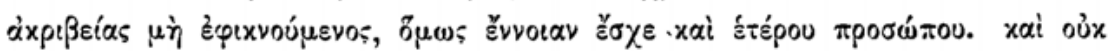

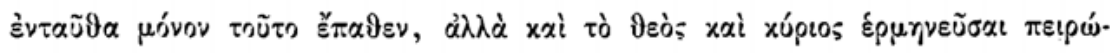

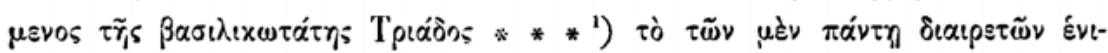

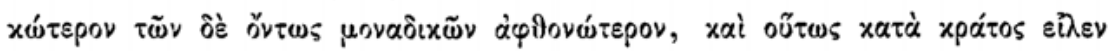

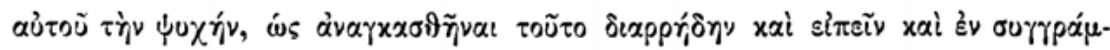

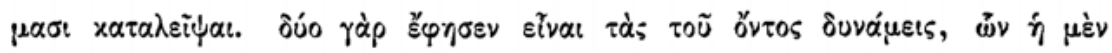

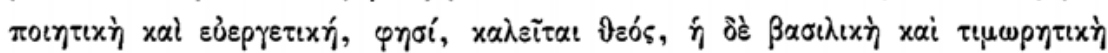
xúpens (cf. Quaest. in Exod. II §68 Harris Fragments p. 67). . . xai

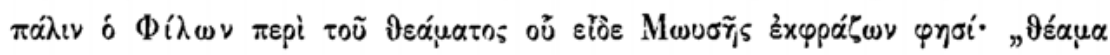

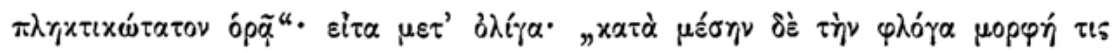

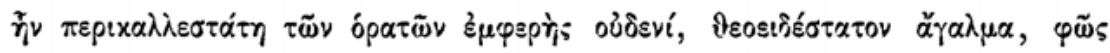

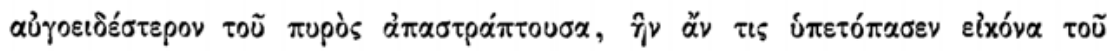

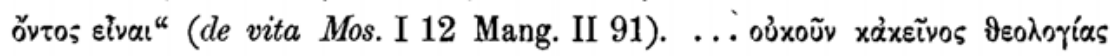

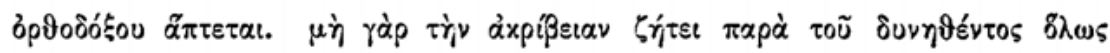

1) post tptáôos propter homoeoteleuton quaedam interciderunt, quae supplenda

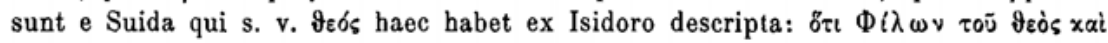

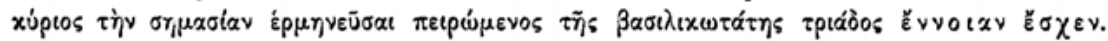

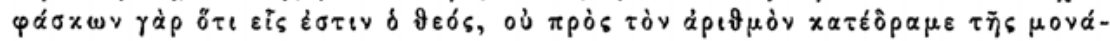

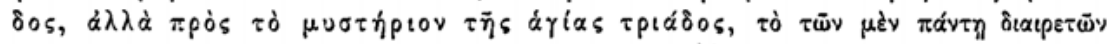

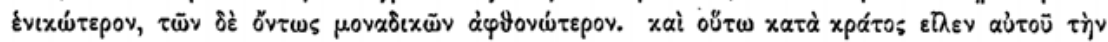

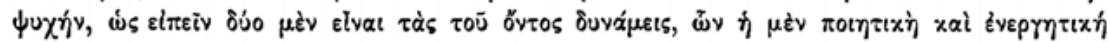

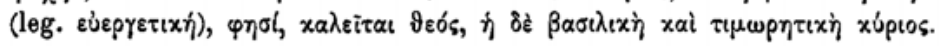




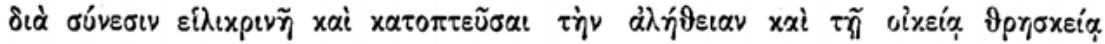

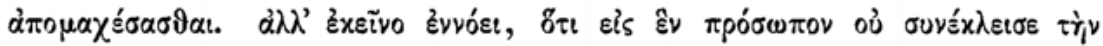

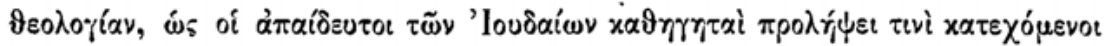

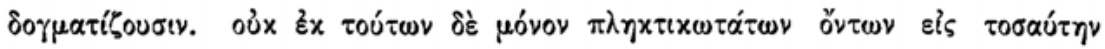

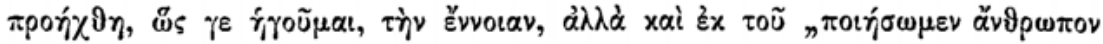

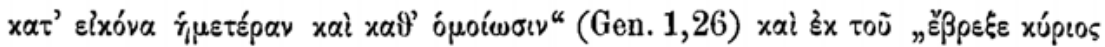

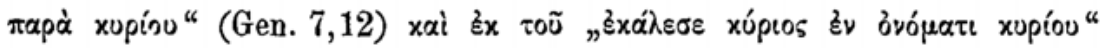

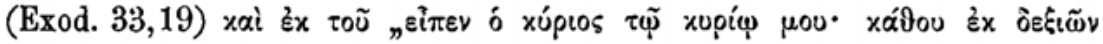

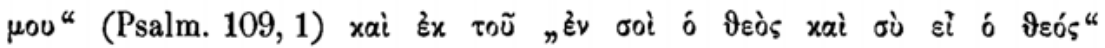

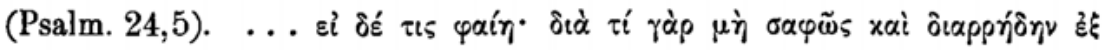

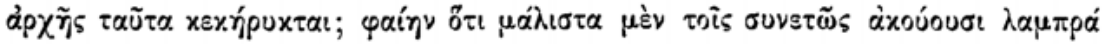

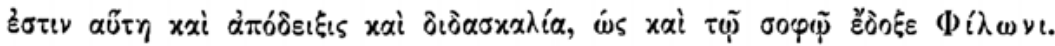

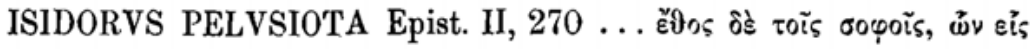

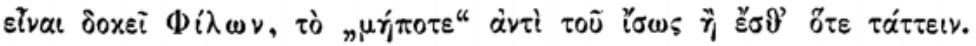

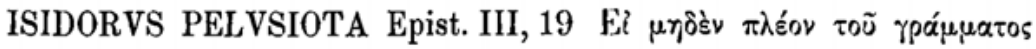

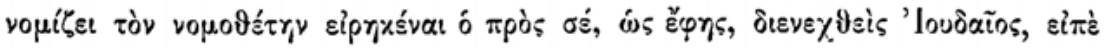

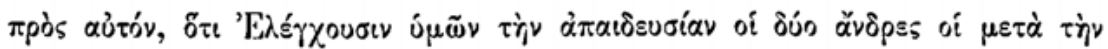

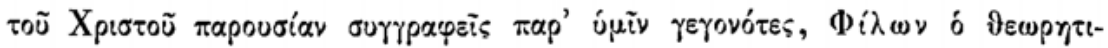
x

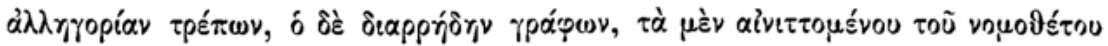

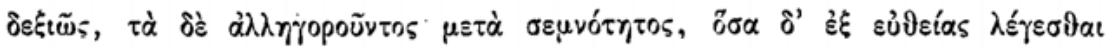

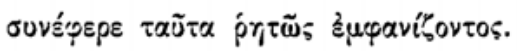

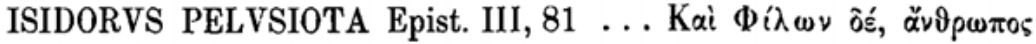

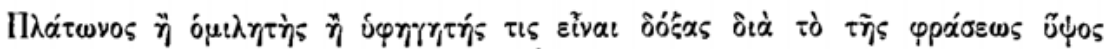

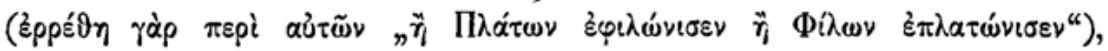

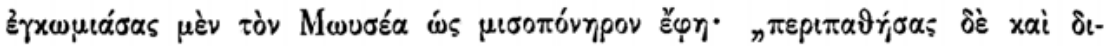

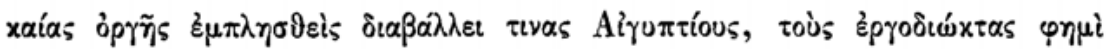

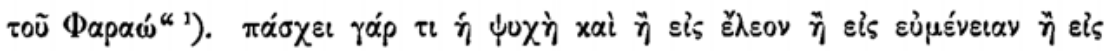

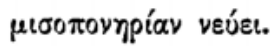

ANASTASIVS SINAITA Viae dux 14 (Migne t. 89 Col. 244) ex

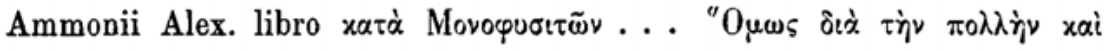

1) locus ab Isidoro allatus apud Philonem non exstat (de re ef. de vita Mosis I 8 p. $87 \mathrm{M}$.). 


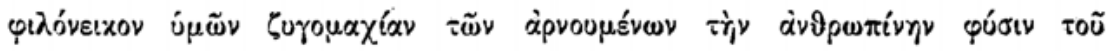

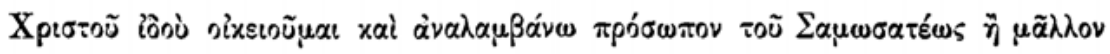

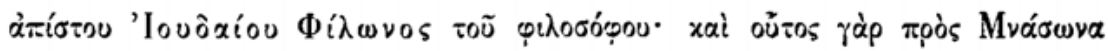

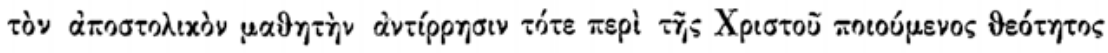

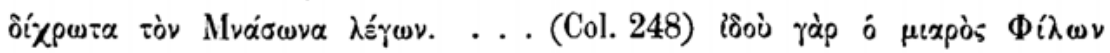

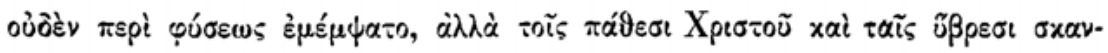

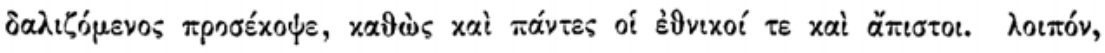

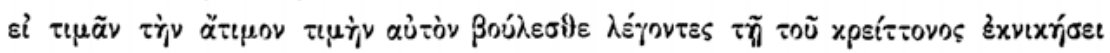

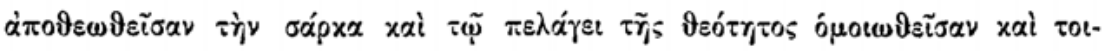

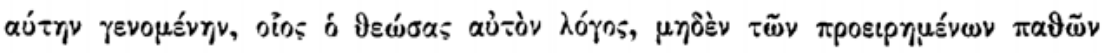

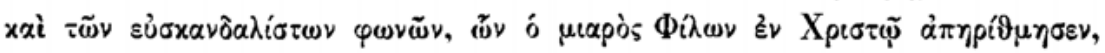

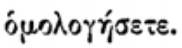

ANASTASIVS SINAITA In Hexaemeron lib. VII (Migne t. 89

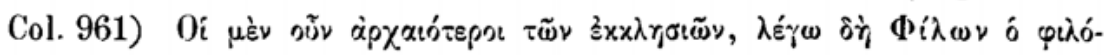

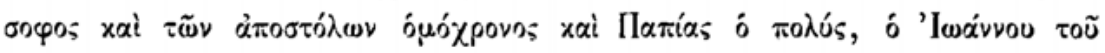

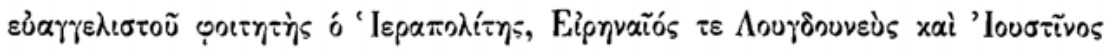

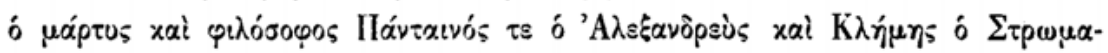

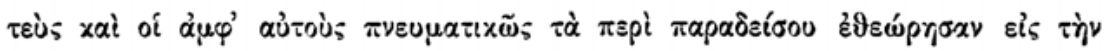

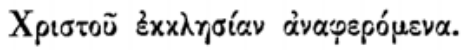

[IOANNES DAMASCENVS] Praef. in Sacra Parallela (Migne t. 95

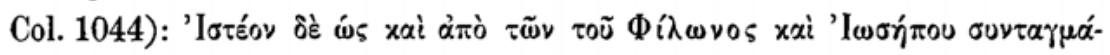

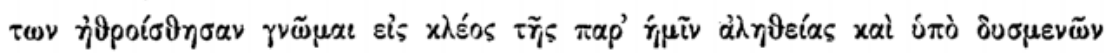

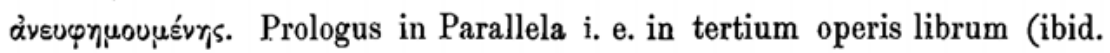

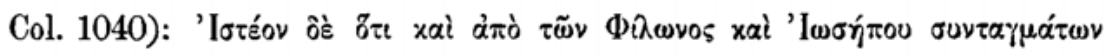

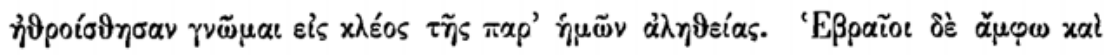

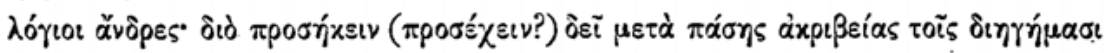

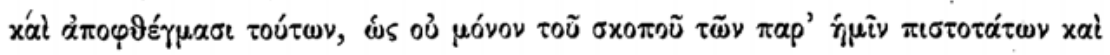

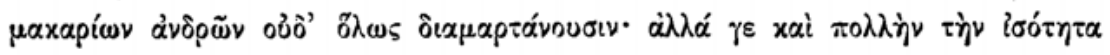

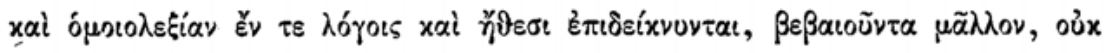

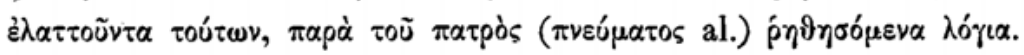

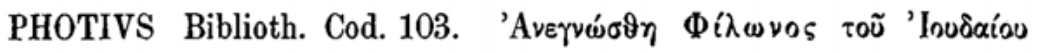

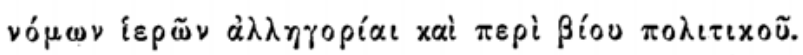

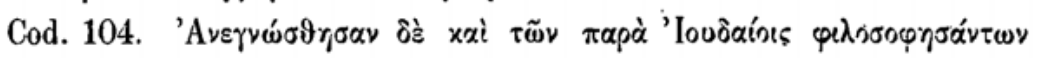




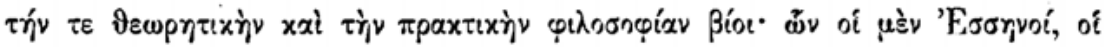

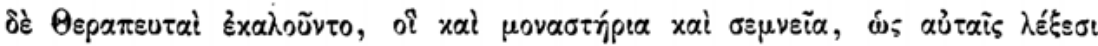

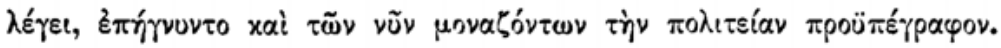

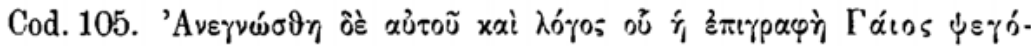

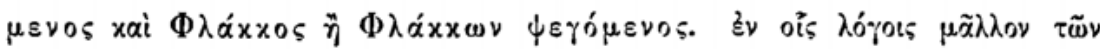

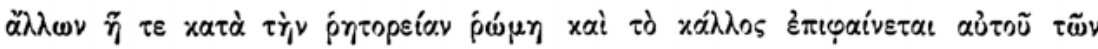

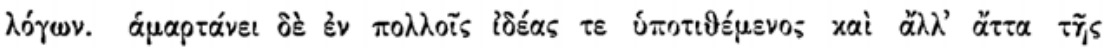

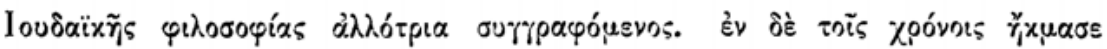

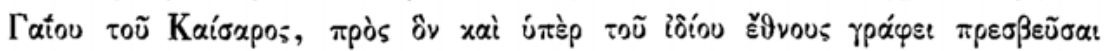

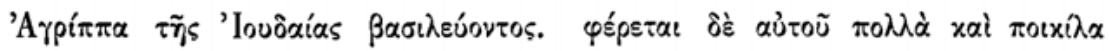

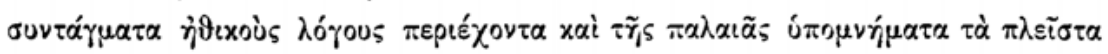

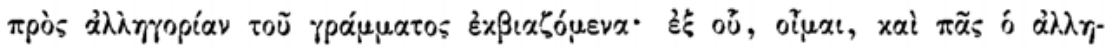

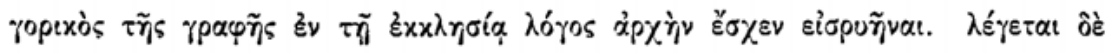

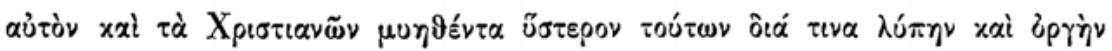

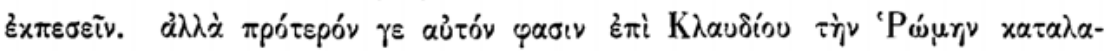

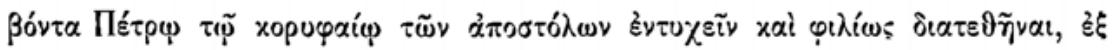

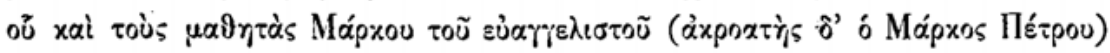

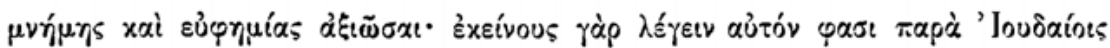

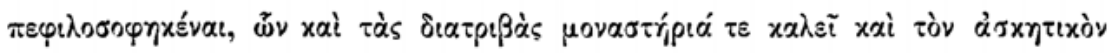

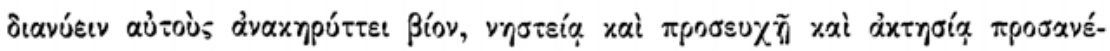

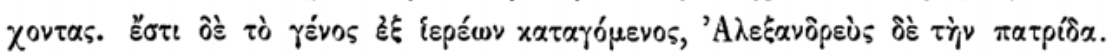

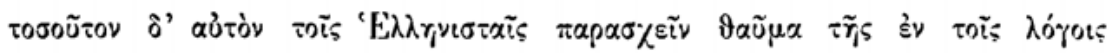

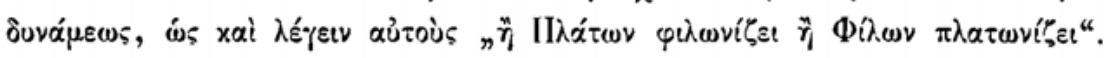

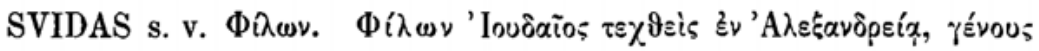

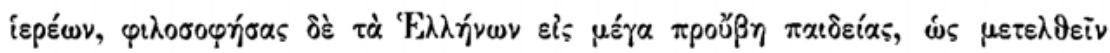

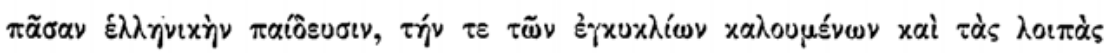

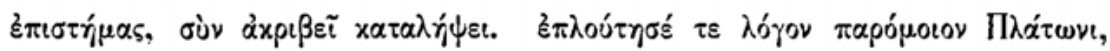

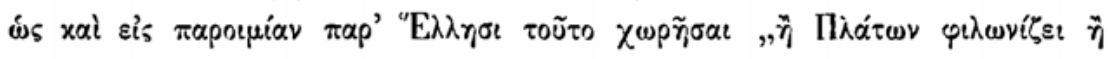

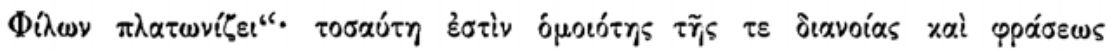

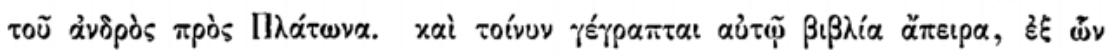

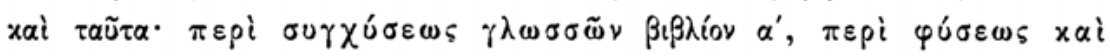

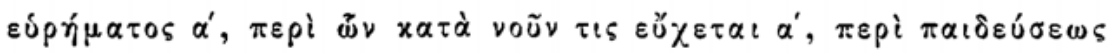

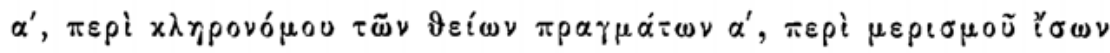

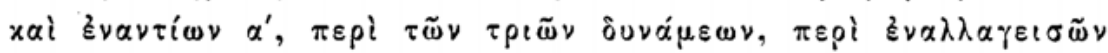




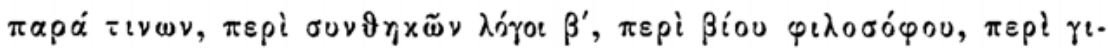

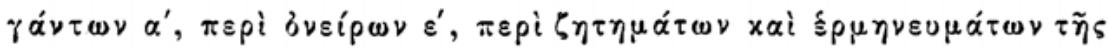

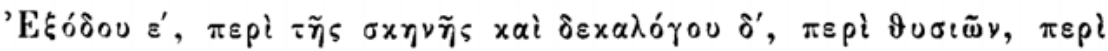

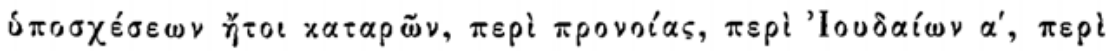

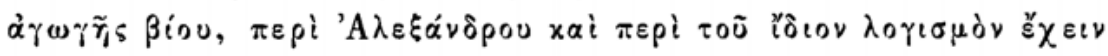

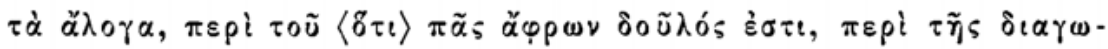

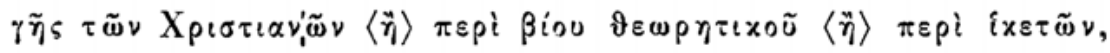

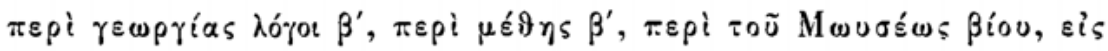

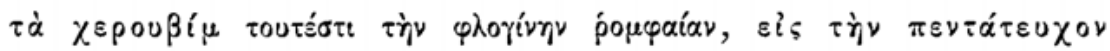

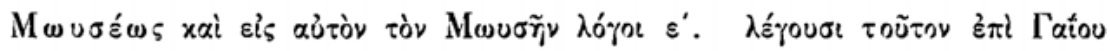

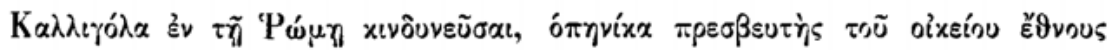

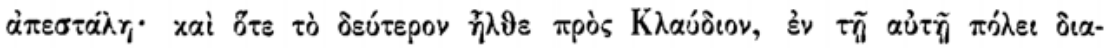

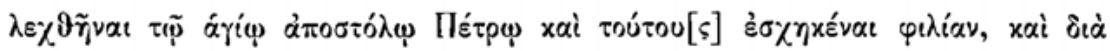

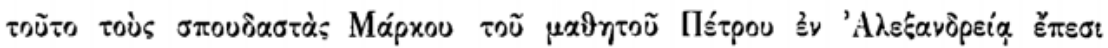

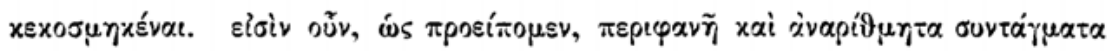

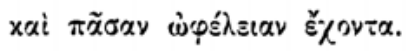

ARETHAS Comment. in Apocalypsin cap. 1 (Migne t. 106 Col. 504)

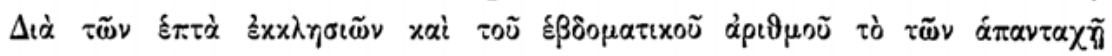

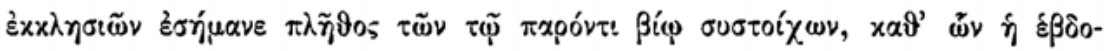

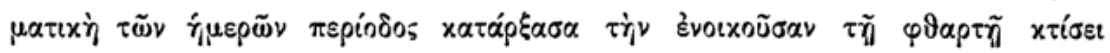

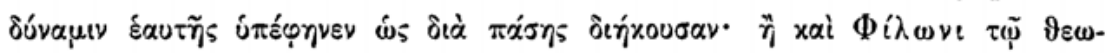

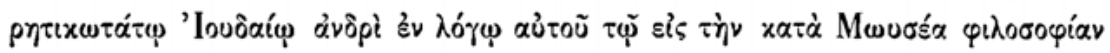

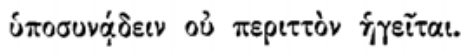

THEODORVS METOCHITA Miscell. cap.16 (p.116 ed. Müller) Пвpi

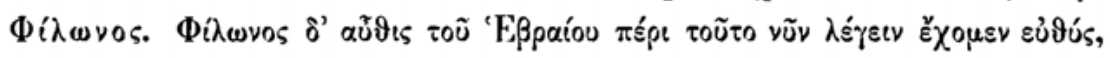

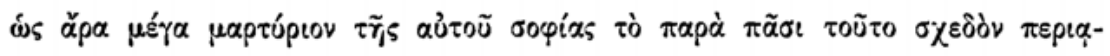

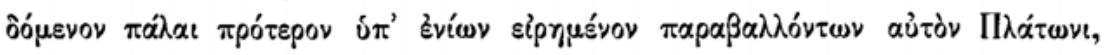

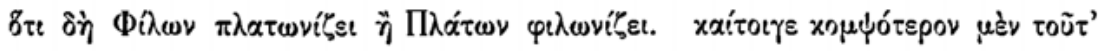

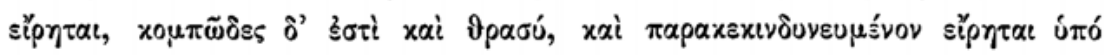

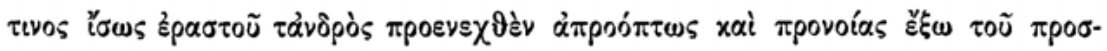

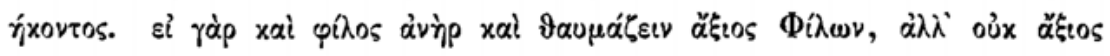

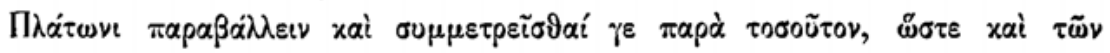

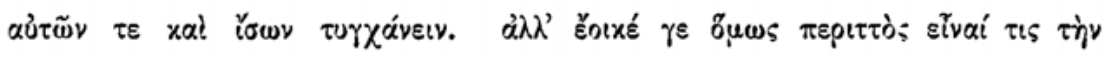




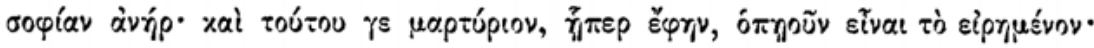

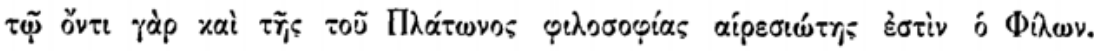

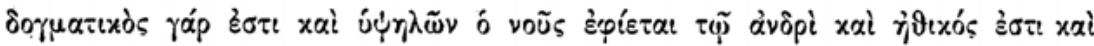

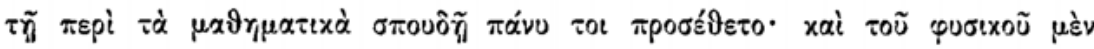

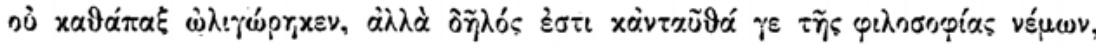

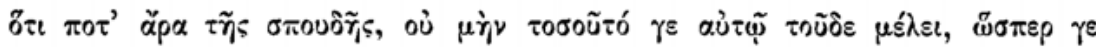

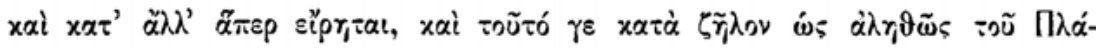

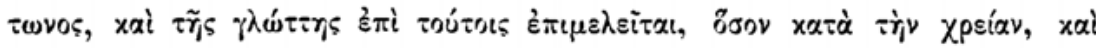

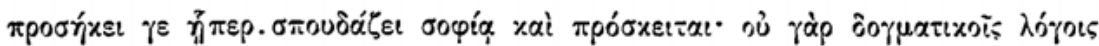

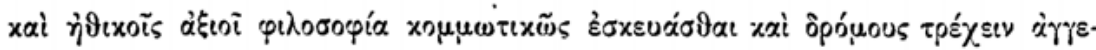

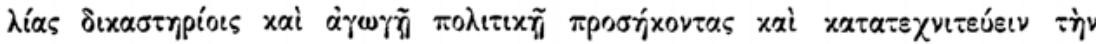

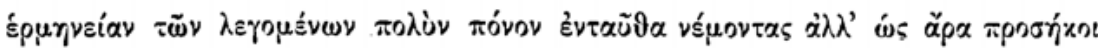

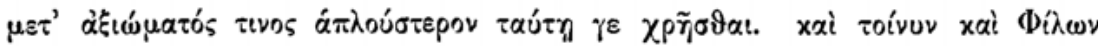

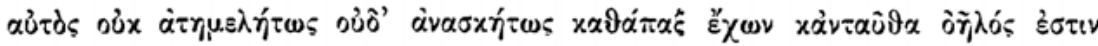

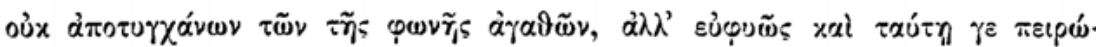

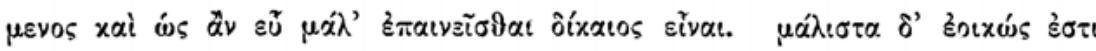

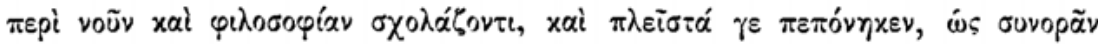

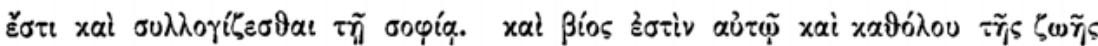

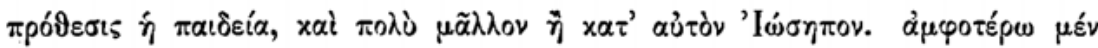

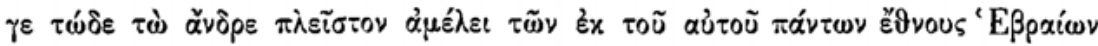

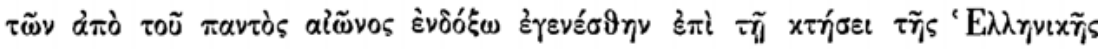

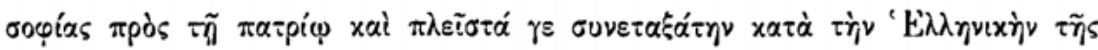

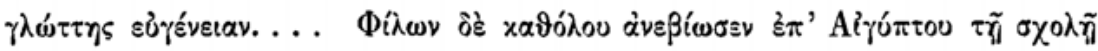

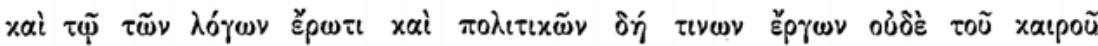

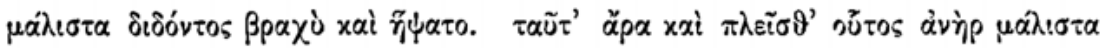

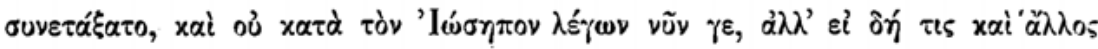

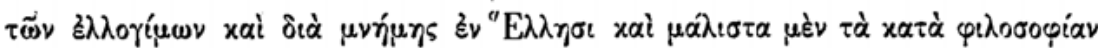

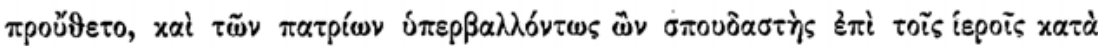

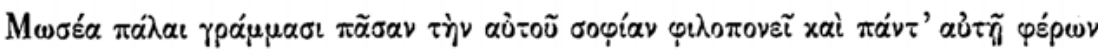

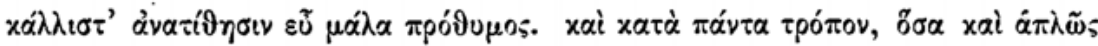

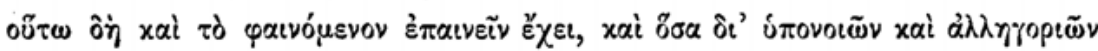

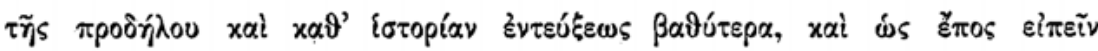

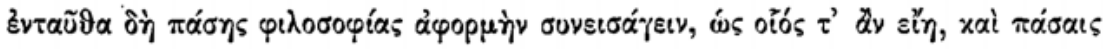

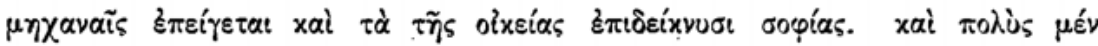

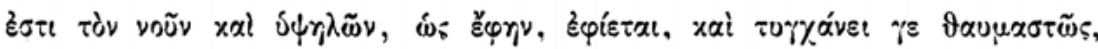




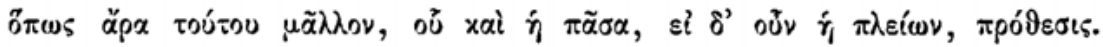

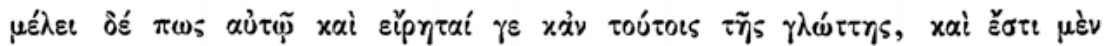

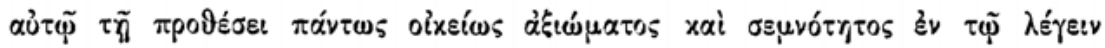

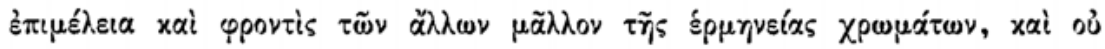

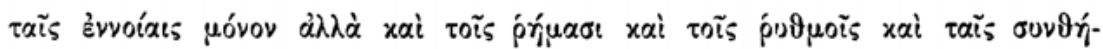

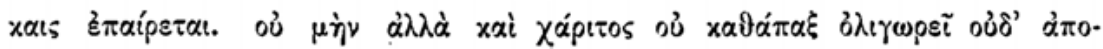

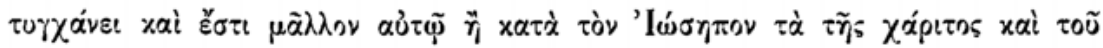

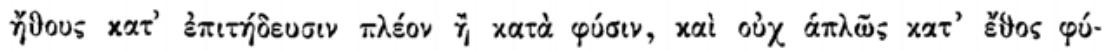

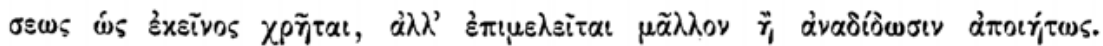

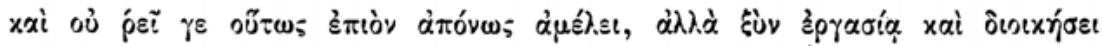

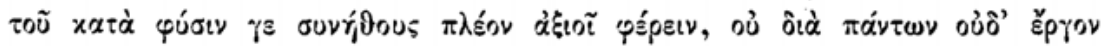

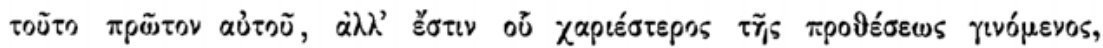

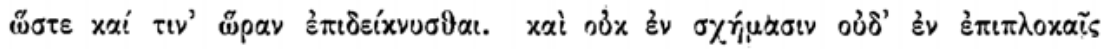

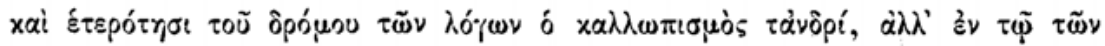

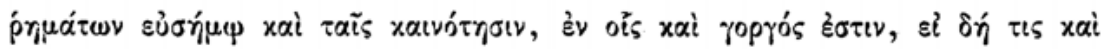

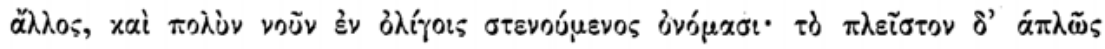

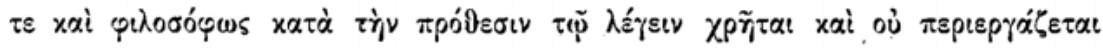

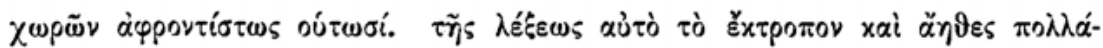

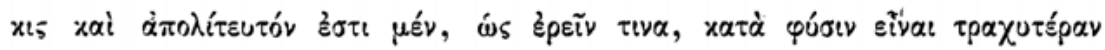

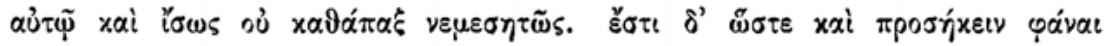

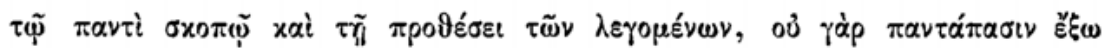

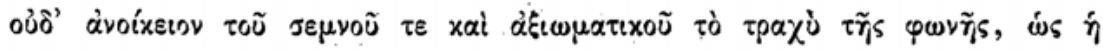

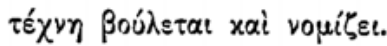

THEODORVS METOCHITA cap. 17 (p. 125 ed. Müller) ... oỉov

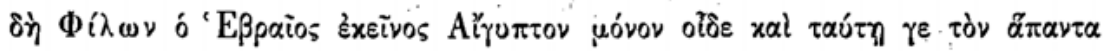

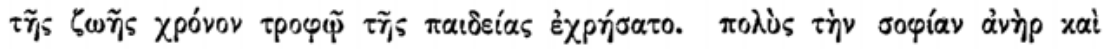

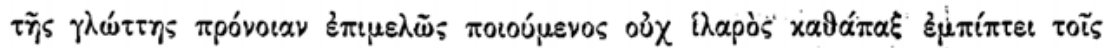

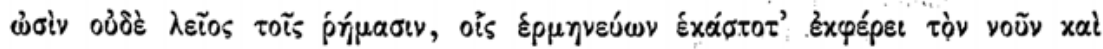

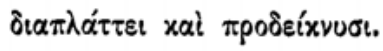

